Spring Technical Meeting

of the Central States Section of the Combustion Institute

March 16-18, 2014

\title{
Cool-flame extinction during n-alkane droplet combustion in microgravity
}

\author{
V. Nayagam ${ }^{1}$, D. Dietrich ${ }^{2}$, M. C. Hicks ${ }^{2}$ and F. A. Williams ${ }^{3}$ \\ ${ }^{1}$ Department of Mechanical and Aerospace Engineering \\ Case western Reserve University, Cleveland, Ohio \\ ${ }^{2}$ NASA Glenn Research Center, Cleveland, Ohio \\ ${ }^{3}$ Department of Mechanical and Aerospace Engineering, UCSD, La Jolla, CA
}

\begin{abstract}
Recent droplet combustion experiments onboard the International Space Station (ISS) have revealed that large n-alkane droplets can continue to burn quasi-steadily following radiative extinction in a low-temperature regime, characterized by negative-temperaturecoefficient (NTC) chemistry. In this study we report experimental observations of n-heptane, $\mathrm{n}$-octane, and n-decane droplets of varying initial sizes burning in oxygen/nitrogen/carbon dioxide and oxygen/helium/nitrogen environments at 1.0, 0.7, and 0.5 atmospheric pressures. The oxygen concentration in these tests varied in the range of $14 \%$ to $25 \%$ by volume. Large n-alkane droplets exhibited quasi-steady low-temperature burning and extinction following radiative extinction of the visible flame while smaller droplets burned to completion or disruptively extinguished. A vapor-cloud formed in most cases slightly prior to or following the "cool flame" extinction. Results for droplet burning rates in both the hot-flame and cool-flame regimes as well as droplet extinction diameters at the end of each stage are presented. Time histories of radiant emission from the droplet captured using broadband radiometers are also presented. Remarkably the "cool flame" extinction diameters for all the three n-alkanes follow a trend reminiscent of the ignition delay times observed in previous studies. The similarities and differences among the n-alkanes during "cool flame" combustion are discussed using simplified theoretical models of the phenomenon.
\end{abstract}

\section{Introduction}

Understanding the combustion characteristics of liquid hydrocarbon fuels is of practical and fundamental importance. The United States alone consumes approximately 19 million barrels of liquid fuels per day which averages out to an amazing 2.5 gallons per day per person [1]. The primary reason for such high reliance on hydrocarbon fuels as the single most important energy source, not only in the US but in the rest of the world, is their high energy density, ease of handling and portability compared to many other forms of energy sources. With the emergence of newer internal combustion engine technologies and renewable bio-fuels, such as the Homogeneous Charge Compression Ignition engine (HCCI) and bio-diesel, that promise cleaner more efficient and sustainable utilization of hydrocarbon fuels, the need to understand the fundamental chemical and physical aspects of liquid fuel combustion is bound to increase.

Commercially available transportation fuels, such as gasoline, diesel, and jet fuel, are comprised of many hydrocarbon compounds, normal alkanes and branched alkanes being the major components. The combustion characteristics of these alkanes are quite complex and follow branched chain reaction pathways involving many intermediate radicals. The chemical pathways vary depending on temperature and to a lesser extent on pressure. In general it is possible to identify a low temperature reaction mechanism and a high temperature mechanism and the 
transition region between them. Many hydrocarbons exhibit a unique feature in the transition region where the reaction rate decreases with increasing temperature called the negative temperature coefficient (NTC) region. Cool flames and the associated multi-stage ignition phenomenon occur in this NTC-controlled region. Researchers in the past, motivated by the "knock" in spark ignition engines associated with cool flames, have used a number of experimental techniques to investigate the cool flame phenomenon including stirred reactors, flow reactors, shock tubes, and rapid compression machines [2]. All these studies primarily involved premixed gases and aimed at understanding the ignition process that transitions from low temperature chemistry to high temperature ignition.

Recent droplet combustion experiments conducted onboard the International Space Station (ISS), as part of the Flame Extinguishment Experiments (FLEX), have revealed for the first time that large n-alkane droplets can continue to burn quasi-steadily in the low-temperature regime, characterized by negative-temperature-coefficient (NTC) chemistry [3]. It was observed that the "cool flame" combustion of the droplet abruptly ends at a finite droplet diameter leaving the unburned droplet to vaporize in the hot ambient. A vapor cloud was also found to form around the droplet as the partially oxidized fuel and other products condensed just prior to or immediately following cool flame extinction. Numerical simulations of spherically symmetric droplet combustion with detailed chemistry that included both high temperature and low temperature kinetics for n-heptane have shown reasonable agreement with these experimental observations $[4,5]$. These experimental and numerical studies provide a new tool to further explore the low temperature chemistry of liquid fuels in an entirely new way. The measured "cool flame" droplet burning rates provide a measure of heat release rate, the flame diameter evolution provides insight into diffusive and convective heat loss effects, and the droplet extinction diameter provides a stringent measurement of chemical-kinetic characteristic times. In this study we report further experimental observations of $n$-decane, $n$-octane, and n-heptane droplets burning in microgravity under varying ambient oxygen and diluent concentrations. It is shown that all three normal alkanes exhibit quasi-steady "cool flame" burning mode followed by cool-flame extinction at a finite droplet diameter. The similarities in cool flame extinction diameter between the three normal alkanes are also discussed.

\section{Experiments}

The experiments were conducted using the Multi-User Droplet Combustion Apparatus installed in the Combustion Integrated Rack (CIR) facility in the US Module of the ISS. The cylindrical combustion chamber in the CIR has a free-volume of approximately 95 liters with the MDCA insert installed. The MDCA used an opposed-needle deployment technique to freely deploy droplets of chosen size in microgravity. When needed it was also possible to use $80 \mu \mathrm{m}$ silicon-carbide fiber to tether the droplet. Ignition of the free droplet was accomplished using two symmetrically positioned hot-wire igniters. The experimental diagnostic system consisted of a black-and-white, back-lit droplet image capture camera, a UV-sensitive flame imaging camera filtered to observe $\mathrm{OH}^{*}$-chemiluminescence at 310 nanometer wave length, and a CCD color camera with a wider view angle. All the camera images are digitally stored on-board the CIR and down-linked at a later time for analysis. The color camera with its real-time down-link capability is also used to conduct experiment operations from the ground at the Telescience Support Center located in NASA Glenn Research Center. The radiant emission from the burning droplet is captured using a broadband (0.6 to $5.0 \mu \mathrm{m}$ range) and a narrowband (5.0 to $7.0 \mu \mathrm{m}$ range) radiometers at $100 \mathrm{~Hz}$ and down-linked along with the image data. Prior to an experimental run, the Fuel and Oxidizer Management Assembly (FOMA) system of the CIR is used to fill the combustion chamber with the desired ambient gas mixture consisting of oxygen, nitrogen, 

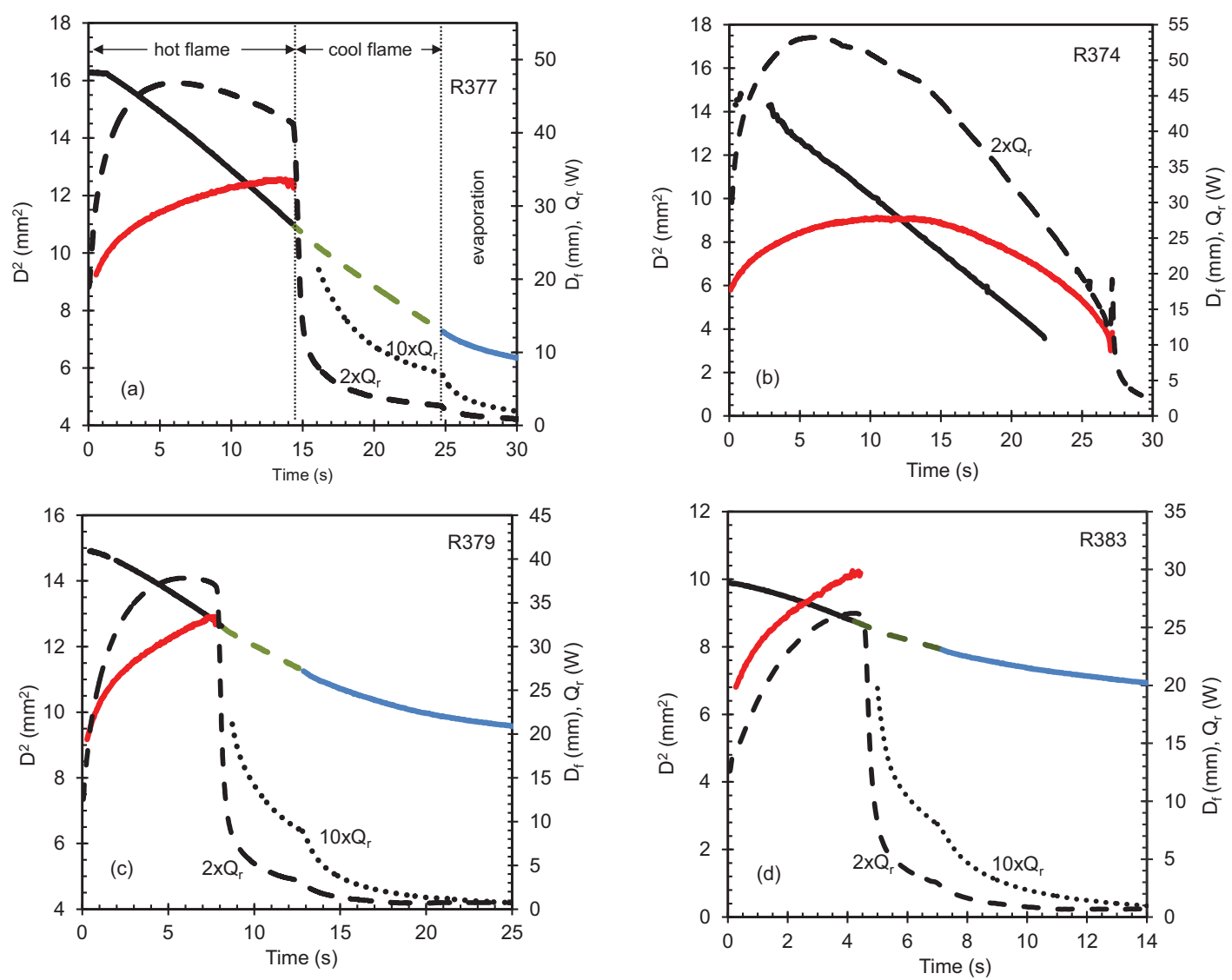

Figure 1: Droplet diameter squared $\mathrm{D}^{2}$, and flame diameter $\mathrm{D}_{f}$ versus time for $\mathrm{n}$-decane droplets burning at 0.5 atm pressure: (a) R377 $\mathrm{D}_{0}=4.03 \mathrm{~mm}, 21 \% \mathrm{O}_{2}$ and $79 \% \mathrm{~N}_{2}$; (b) R374 $\mathrm{D}_{0}=3.79$ $\mathrm{mm}, 25 \% \mathrm{O}_{2}$ and $75 \% \mathrm{~N}_{2}$; (c) R379 $\mathrm{D}_{0}=3.86 \mathrm{~mm}, 17 \% \mathrm{O}_{2}$ and $83 \% \mathrm{~N}_{2}$; (d) R383 $\mathrm{D}_{0}=3.14 \mathrm{~mm}$, $14 \% \mathrm{O}_{2}$ and $96 \% \mathrm{~N}_{2}$; Radiative heat loss $\mathrm{Q}_{r}$ measured using a broadband (dashed line) and a narrowband (dotted line) radiometers are also shown.

and either carbon dioxide or helium at a selected pressure. Typically several droplet burns were performed in each environment before venting the combustion chamber to space vacuum and refilling. Further details of experiments and operational procedures can be found in Dietrich et al.[6].

\section{Results and Discussions}

Over three hundred droplet combustion tests were completed as part of the FLEX experiments using three different normal alkane fuels and two different alcohol fuels in a variety of diluent substituted environments at ambient pressures in the range of 0.5 to $3 \mathrm{~atm}$ to date. The droplet initial diameters in these tests varied from approximately $1.5 \mathrm{~mm}$ to $5 \mathrm{~mm}$ depending upon the ambient gas mixture composition and pressure, so that both diffusive and radiative extinctions can be observed and the flammability boundaries as a function of diluent concentrations can be developed. Here we present selected results for normal alkanes fuel droplets with the view toward understanding the cool flame combustion and extinction.

\subsection{N-decane Results}

Figure 1 shows the measured droplet diameter squared $\mathrm{D}^{2}$, and the flame diameter $\mathrm{D}_{f}$ as a 
function of time for four different n-decane droplets. Figure 1a (R377) corresponds to a n-decane droplet with an initial diameter of $4.03 \mathrm{~mm}$ burning in $21 \%$ oxygen and $79 \%$ nitrogen mixture at $0.5 \mathrm{~atm}$ pressure. Also shown in Fig. 1a are the radiative power output from the droplet measured using a broadband and a narrowband radiometers. Following ignition, the diameter of the diffusion flame $\mathrm{D}_{f}$ surrounding the droplet increases with time before extinguishing abruptly at around 14.6 seconds. The radiative heat loss from the flame zone initially increases with time and then decreases slightly prior to visible flame extinction as seen from the broadband radiometer output. The narrowband radiometer saturates during this first-stage, hot-flame combustion and it is not shown. Even though the maximum heat loss due to radiation occurs around 5 second, flame extinction occurs only later on when the droplet diameter has decreased sufficiently to reduce the residence time in the flame zone. The hot-flame extinction is clearly demarcated by the sudden drop in broadband radiometer output. The second-stage combustion termed "cool flame" zone starts immediately following hot-flame extinction. As in the hot-flame region the square of the droplet diameter decreases linearly with time in the cool-flame region, but at a slightly slower rate. Both the color camera and the UV-camera are not sensitive enough to register any flame images during this period. Both the broadband and narrowband radiometers, however, register continued radiative heat loss from the droplet indicating active chemical heat release. The end of "cool flame" combustion is clearly marked by the rapid drop in the narrowband radiometer output. Following cool flame extinction the droplet simply evaporates in the hot environment and the radiative loss measurements decay to zero values without any further abrupt changes. The burning rate constants $\mathrm{K}\left(=\mathrm{dD}^{2} / \mathrm{dt}\right)$ corresponding to the first and second stage combustion were found to be 0.41 and $0.33 \mathrm{~mm}^{2} / \mathrm{s}$ respectively. The combustion behavior exhibited in Fig 1a is typical for most large $n$-alkane droplets that undergo radiative extinction though some subtle differences can be observed when the initial droplet size, the ambient oxygen concentration, or the diluent concentrations are altered.

Figure $1 \mathrm{~b}$ (R374) shows the combustion characteristics for a $3.79 \mathrm{~mm}$-decane droplet burning at a slightly increased oxygen concentration of $25 \%$ and the rest being nitrogen at $0.5 \mathrm{~atm}$ pressure. The visible flame diameter initially increases with time and then it decreases until the droplet micro-explodes 26 seconds after ignition. Clearly, the increased ambient oxygen concentration moves the flame closer to the droplet surface due to stoichiometric requirements at the flame front and thus precludes the radiative extinction observed before. Visible flame extinction in this case occurs at much smaller droplet size with a micro-explosion. The droplet moves outside the droplet-view camera field of view toward the end of the burn. The calculated burning rate constant was $0.52 \mathrm{~mm}^{2} / \mathrm{s}$ for the duration the droplet remained in the field of view. It is also interesting to note that the radiative heat loss from the flame is higher than the previous case due to the increased flame temperature resulting from higher oxygen concentration.

The effects of reducing the oxygen concentration on the burning behavior is displayed in Fig. 1c (R379). The initial droplet diameter for this test was $3.86 \mathrm{~mm}$ and ambient environment was made of $17 \% \mathrm{O}_{2}$ and $83 \% \mathrm{~N}_{2}$ mixture at $0.5 \mathrm{~atm}$. With the reduced oxygen concentration the overall radiative heat loss decreases due to reduced flame temperature. However, radiative extinction occurs at 7 seconds due to increased flame dimension at this lower ambient oxygen level. The burning rate constants for the first and second stage combustion were 0.31 and 0.27 $\mathrm{mm}^{2} / \mathrm{s}$, respectively. A further reduction in $\mathrm{O}_{2}$ concentration to $14 \%$ leads to similar behavior as shown in Fig. 1d (R383). The reduced oxygen concentration also leads to earlier extinctions in both hot and cool flame regime and the $\mathrm{K}$ values for these two regimes were 0.29 and 0.25 $\mathrm{mm}^{2} / \mathrm{s}$, respectively. In general it can be summarized based on the results presented in Fig. 1 that reducing the ambient oxygen concentration leads to earlier hot and cool flame extinctions. 

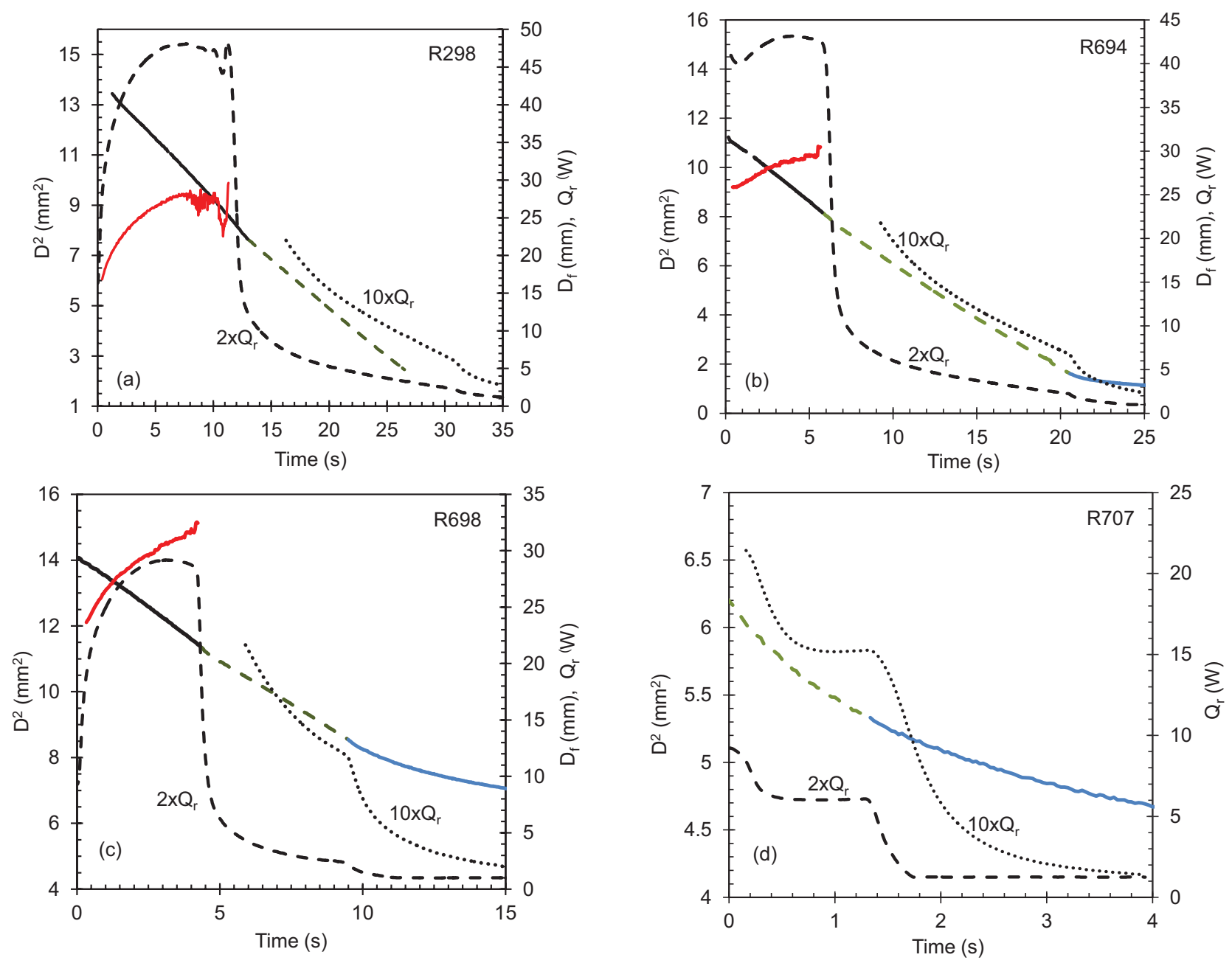

Figure 2: Droplet diameter squared versus time for an n-octane droplets burning at 1 atm pressure: $\mathrm{O}_{2} / \mathrm{He} / \mathrm{N}_{2}$ molar fractions are (a)R298 (0.21/0.0/0.79), (b)R694 (0.21/0.15/0.64), (c)R698 (0.21/0.50/0.29), and (d) R707 (0.21/0.75/0.04).

When the oxygen concentration is sufficiently high radiative extinction is avoided and visible flame extinction occurs at a much smaller droplet size either by micro-explosion of the droplet or by diffusive extinction.

\subsection{N-octane Results}

The burning characteristics of four different n-octane droplets burning in oxygen/helium/nitrogen mixtures at one atmospheric pressure are shown in Fig. 2. In these tests the helium dilution is gradually increased at expense of nitrogen while the oxygen mole fraction is held constant at 0.21. Test R298 results shown in Fig. (2a) corresponds to a droplet with $\mathrm{D}_{0}=3.6 \mathrm{~mm}$ burning in air $\left(\mathrm{O}_{2}: \mathrm{N}_{2}=0.21: 0.79\right)$ with no helium dilution. Both hot-flame and cool-flame burning modes were found to exist with the respective burning rates of 0.48 and $0.38 \mathrm{~mm}^{2} / \mathrm{s}$. Prior to extinction the visible flame showed an oscillatory instability where the flame develops a hole which opened and closed quickly before complete flame extinction. This flame oscillation is clearly captured by the broadband radiometer output. The $\mathrm{D}_{f}$ values obtained by fitting a circle to the UV-image of the droplet and calculating an effective flame diameter from the area of the circle is unable to 


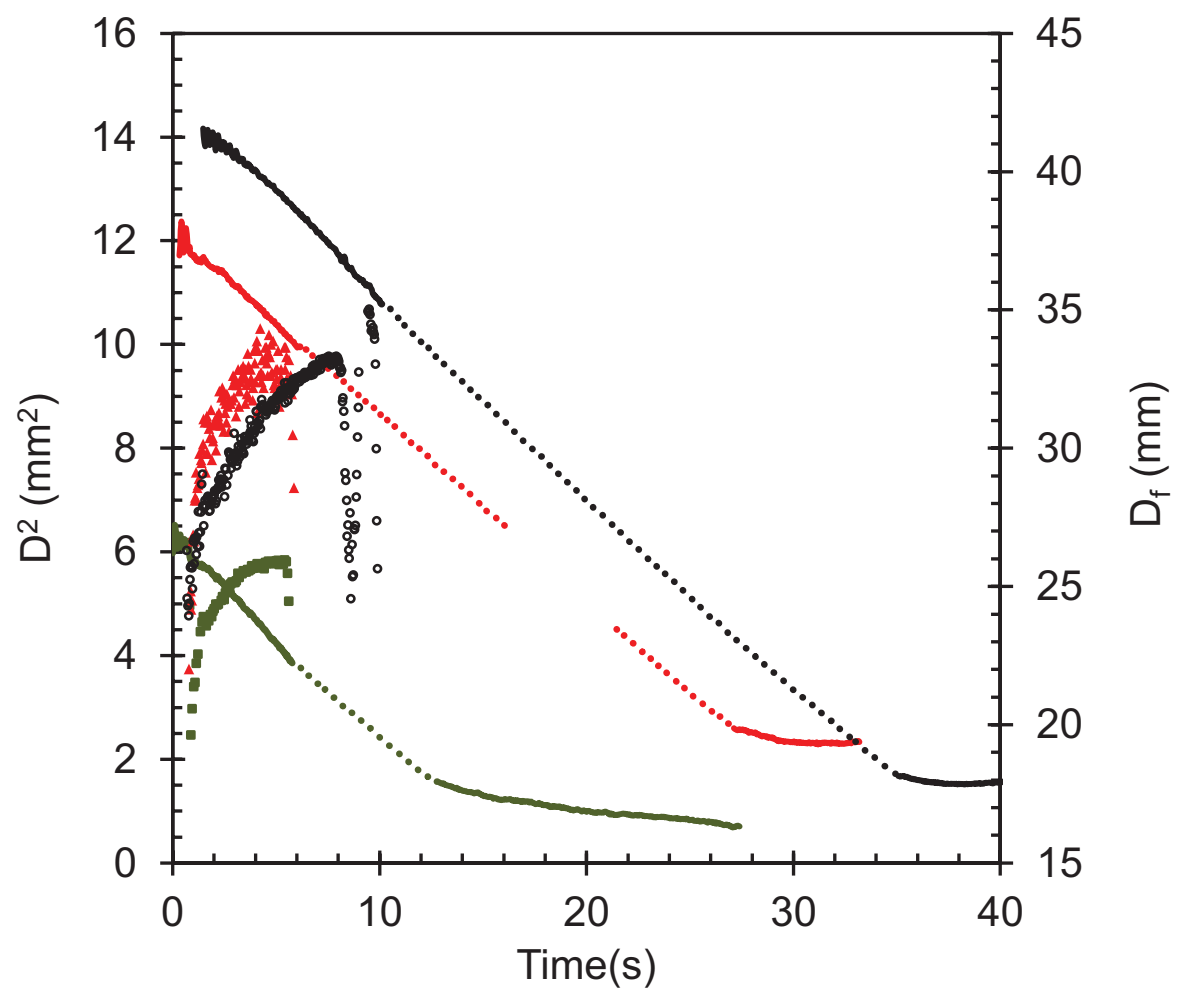

Figure 3: N-heptane droplets burning in oxygen/carbon dioxide/nitrogen environments showing cool-flame second stage quasi-steady combustion and extinction.

faithfully capture this oscillation. The second stage extinction was not recorded by the dropletview camera because the droplet drifted out of the field of view. However, the radiometers with their larger field of view were able to capture cool flame extinction occurring at 30.5 seconds. In test R694 shown Fig. (2b) 15\% helium by volume is added at the expense of nitrogen to the ambient gas mixture and $\mathrm{D}_{0}$ was $3.37 \mathrm{~mm}$, slightly smaller than R298. The first and second stage burning rates are now 0.54 and $0.43 \mathrm{~mm}^{2} / \mathrm{s}$, respectively, which is slightly higher than R298 due to increased thermal conductivity of helium compared to nitrogen. The overall radiative heat losses from the flames are similar in both cases though helium dilution decreases the flame temperature and reduces the peak radiative heat loss rate for test R694. However, the burning times in both stages have been considerably shortened by the addition of helium as predicted in [4]. Helium dilution level is further increased to $50 \%$ by volume in test R698 which had $D_{0}=$ $3.6 \mathrm{~mm}$. The first and first and second stage burning rate constants were 0.63 and $0.53 \mathrm{~mm}^{2} / \mathrm{s}$, respectively. When helium dilution was increased to $75 \%$ by volume in test $\mathrm{R} 707$ for $\mathrm{D}_{0}$ of 2.49 $\mathrm{mm}$ first stage burning is almost eliminated (see, Fig. (2d)). The hot flame that formed during the ignition dies within a fraction of a second and the cool flame burning commences immediately which also ends quickly leaving the droplet to evaporate. The high thermal conductivity of helium leads to large heat loss from the flame zone and as a consequence the flame temperature rapidly decreases leading to cool flame extinction. The entire process was transient and quasisteady burning was not achieved.

\subsection{N-heptane Results}

Detailed results for $n$-heptane droplets burning in oxygen/carbon dioxide/nitrogen mixtures were presented earlier [3]. We summarize those results here for the sake of completeness. Figure 
3 shows three typical free-floated cases, corresponding to ambient gas mixtures of $21 \%$ oxygen $79 \%$ nitrogen, $18 \%$ oxygen $82 \%$ nitrogen, and $18 \%$ oxygen $67 \%$ nitrogen $15 \%$ carbon dioxide, all by volume, at one atmospheric pressure. The initial diameters for these cases respectively were $3.91,3.48$, and $2.49 \mathrm{~mm}$. All three cases exhibit radiative extinction followed by cool flame combustion and the second stage extinction leading to pure vaporization. The cool flame extinction diameters for all the three alkanes fuels are further discussed in the following section.

\subsection{Cool flame extinction}

Even though the cool flame phenomenon has been extensively studied in the past, the primary focus has been toward understanding the ignition characteristics of hydrocarbon fuels rather than the extinction process encountered during droplet combustion. However, since both ignition and extinction of a flame are controlled by the underlying chemical kinetic mechanisms there has to be certain similarities between them. It has been shown using computations with detailed chemistry [7] that the ignition delay times for stoichiometric n-alkanes burning in air with carbon numbers in the range from 7 to 16 remain almost identical, a result that has ample experimental support. Therefore, one could expect such similarities in diffusion flame extinction in the low temperature regime as well. To test such a hypothesis, guided by a preliminary theoretical study that assumes constant thermophysical properties, we plot the cool flame extinction diameter as a function of oxygen molar concentration, $\mathrm{C}_{\mathrm{O}_{2}}$, in Fig. $4 \mathrm{a}$. The data points are restricted to $\mathrm{O}_{2} / \mathrm{N}_{2}$ mixtures only because of the need to keep the gas-phase thermophysical properties as constant as possible, to conform with the theory. Figure 4a shows the cool flame extinction diameter $\mathrm{D}_{c e}$ plotted against oxygen molar concentration along with a line that has a slope of $-3 / 4$, as suggested by the theory.

The basis of this choice for plotting the data arises from rough ideas about the NTC chemistry. The heptyl radical $\mathrm{R}$ can react in two differen ways. It can be attacked by radicals or decompose unimolecularly, in either event with an effective unimolecular rate constant having an activation energy around $120 \mathrm{~kJ} / \mathrm{mol}$, leading to the high temperature path, or an oxygen molecule can be added to $\mathrm{R}$ to form the ROO radical, with effectively zero activation energy, leading to the low temperature chemistry. The NTC region is centered where these two rates are equal, meaning that there is a crossover temperature for NTC that changes with the oxygen concentration in such a way that the oxygen concentration at crossover varies with the crossover temperature in an Arrhenius manner with an effective activation energy of about $120 \mathrm{~kJ} / \mathrm{mol}$. The low-temperature path is known to proceed to form ketohydroperoxides, the unimolecular decomposition of which, with an activation energy of about $180 \mathrm{~kJ} / \mathrm{mol}$, provides the branching that carries the low temperature ignition chemistry. The low temperature diffusion flame is stable only in the NTC region, and so extinction occurs at a droplet diameter where the low temperature branching rate becomes comparable with the consumption rate of $\mathrm{R}$. This means that the characteristic chemical time at extinction corresponds to a reaction rate with an activation energy of about $180 \mathrm{~kJ} / \mathrm{mol}$, at about the crossover temperature. The corresponding chemical time therefore decreases with increasing oxygen concentration roughly as the oxygen concentration raised to the power $-180 / 120=-3 / 2$. In droplet burning, the square of the diameter decrease linearly with time, whence the observed extinction diameter should be approximately proportional to the oxygen concentration raised to the power $-3 / 4$.

The prediction of this simplified theory seems to be in reasonable agreement with the experiments, within the scatter of the data, in Fig. 4a. This type of comparison, however, is not appropriate when the data with different inert diluents are addressed because they introduce different diffusivities that lead to different burning rate constants. The replacement of nitrogen with 

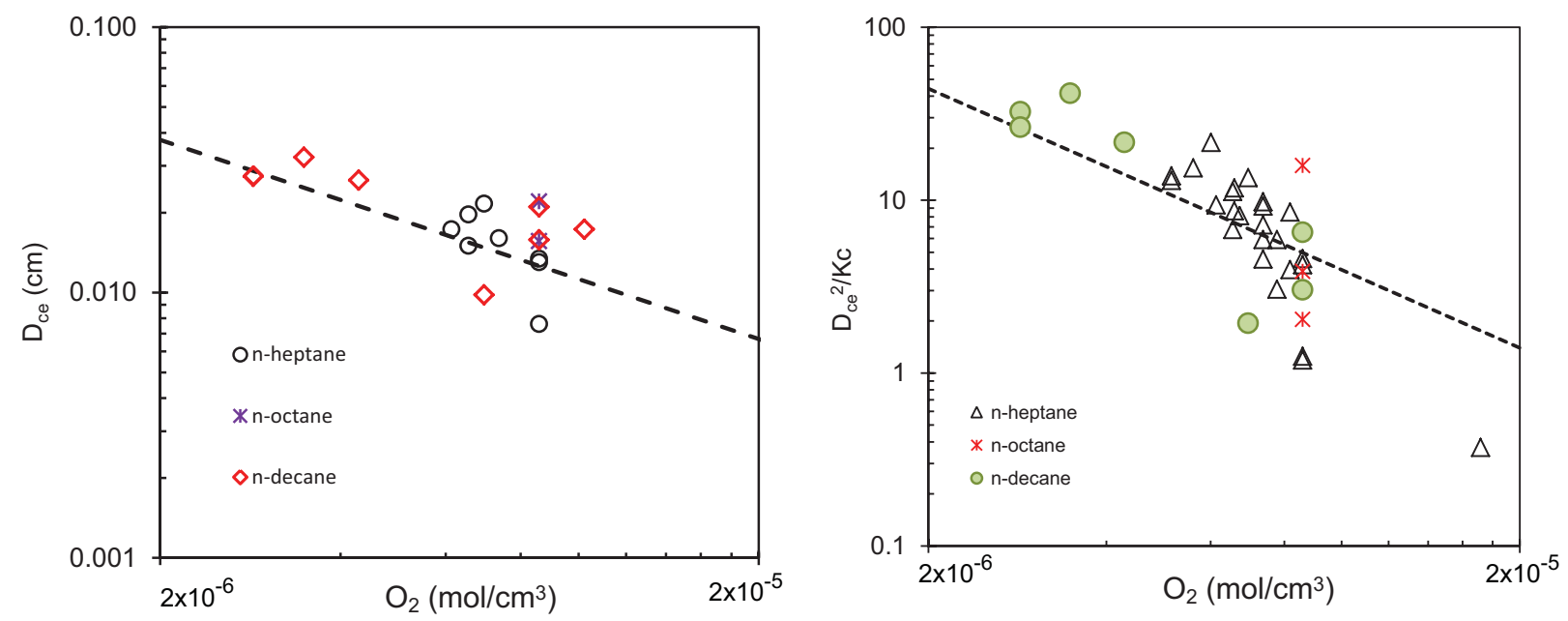

Figure 4: Cool flame extinction diameters as a function of ambient oxygen molar concentration for n-alkane droplets: (a) $\mathrm{O}_{2} / \mathrm{N}_{2}$ environments, and (b) diluent substituted environments.

carbon dioxide or helium increases the heat loss from the flame zone, carbon dioxide through its radiative participation $[4,8]$, and helium through its high thermal conduction [4]. Furthermore, the heat transfer back to the fuel droplet is also altered by diluent replacement, and consequently the droplet burning rates. The increased heat loss from the flame zone leads to a reduction in the flame temperature. Since the thermal conductivity of $\mathrm{CO}_{2}$ is close to that of $\mathrm{N}_{2}$, the reduction in flame temperature leads to a reduction in burning rate for $\mathrm{CO}_{2}$ dilution. On the other hand, helium thermal conductivity is almost 10 times that of nitrogen and when helium is substituted for nitrogen the increased thermal conductivity increases the heat feed back to the droplet and increases the burning rate even though the flame temperature is reduced. The interactions of thermally participating diluent gases with the overall process of cool flame extinction is complicated and even simplified theoretical descriptions of this problem are not yet available.

To account in an approximate way for these effects, It is useful to employ the experimental burning rate constants $\mathrm{K}_{c}$ to construct a time scale from the observed extinction diameters. In this way, the influences of the different diffusivities of the different diluents are reduced. Following this concept, we plot the residence time at extinction obtained from the experimental measurements, namely $\mathrm{D}_{c e}^{2} / \mathrm{K}_{c}$, against a chemical time which is proportional to $\mathrm{C}_{\mathrm{O}_{2}}$ in Figure 4b. The data points include both carbon dioxide, and helium dilution cases, as well as $\mathrm{O}_{2} / \mathrm{N}_{2}$ mixture cases at different pressures. Remarkably the data are reasonably well correlated, considering the number of variables involved in the experiments, and, within the appreciable scatter, the results are in agreement with the theoretical slope of $-3 / 2$. In some sense this is not surprising because the cool flame phenomenon takes place in a narrow temperature range, unlike the hot flame, and the oxygen molar concentration by itself seems to sufficiently represent the variation of the chemical time. Ideally $\mathrm{K}_{c}$ should be replaced by an expression based on more detailed independent variables. At the present level of treatment, however, the results seem encouraging.

\section{Concluding Remarks}

Experimental results for $n$-heptane, n-octane, and n-decane droplets burning in mixtures of oxygen/diluent/nitrogen mixtures at three different pressures are presented. It is shown that all three normal alkanes exhibit cool-flame burning following radiative extinction of the hot flame. 
The cool flame burning rates are slightly lower compared to the hot flame rates. The cool flame extinction diameters vary as oxygen molar concentration to the power $-3 / 4$ for oxygen/nitrogen mixture. When nitrogen is replaced by either helium or carbon dioxide the extinction diameter does not follow the $\mathrm{C}_{\mathrm{O}_{2}}^{-3 / 4}$ trend. But, it is shown that the measured residence time $\mathrm{D}_{c e}^{2} / \mathrm{K}_{c}$ can be correlated against the oxygen molar concentration $\mathrm{C}_{\mathrm{O}_{2}}$, which is proportional to the chemical time in the NTC region. Further theoretical investigation are needed to better understand the cool flame extinction behavior and to quantify the influences of diluent gases which are currently underway.

\section{Acknowledgments}

The authors would like to thank the FLEX team members Profs. T.Avedisian, M.Y.Choi, T.Farouk, F.Dryer,and B. Shaw. This work was supported by the NASA Space Life and Physical Sciences Research and Applications Program and the International Space Station Program. Mr. J. Mark Hickman served as the project manager.

\section{References}

[1] Rolf D. Reitz. Directions in internal combustion engine research. Combustion and Flame, 160(1): $1-8,2013$.

[2] Charles K Westbrook. Chemical kinetics of hydrocarbon ignition in practical combustion systems. Proceedings of the Combustion Institute, 28(2):1563-1577, 2000.

[3] Vedha Nayagam, Daniel L. Dietrich, Paul V. Ferkul, Michael C. Hicks, and Forman A. Williams. Can cool flames support quasi-steady alkane droplet burning? Combustion and Flame, 159(12):3583 - 3588, 2012.

[4] Tanvir I. Farouk and Frederick L. Dryer. Isolated n-heptane droplet combustion in microgravity: "cool flames" two-stage combustion. Combustion and Flame, 161(2):565 - 581, 2014.

[5] A. Cuoci, A. Frassoldati, T. Faravelli, and E. Ranzi. Cool flames in droplet combustion. XXXVI Meeting of the Italian Section of the Combustion Institute, 2013.

[6] D. L. Dietrich, P.V. Ferkul, V.M. Bryg, V. Nayagam, M.C. Hicks, F.A. Williams, F.L. Dryer, B.D. Shaw, M.Y. Choi, and C.T. Avedisian. Detailed results from the flame extinguishment experiment (FLEX). Technical Publication NASA/TP-2013-216046, NASA, Glenn Research Center, Cleveland OH 44135, USA, 2013.

[7] Charles K Westbrook, William J Pitz, Olivier Herbinet, Henry J Curran, and Emma J Silke. A comprehensive detailed chemical kinetic reaction mechanism for combustion of $n$-alkane hydrocarbons from $n$-octane to $n$-hexadecane. Combustion and Flame, 156(1):181-199, 2009.

[8] Justin Dzik, Vedha Nayagam, and Forman A Williams. Ignition and combustion of n-heptane droplets in carbon dioxide enriched environments. International Communications in Heat and Mass Transfer, 37(3):221-225, 2010. 